\title{
Invited review: Practical feeding management recommendations to mitigate the risk of subacute ruminal acidosis in dairy cattle
}

\author{
E. Humer, ${ }^{*}$ R. M. Petri, ${ }^{*}$ J. R. Aschenbach,† B. J. Bradford,‡ G. B. Penner,§ M. Tafaj,\# K.-H. Südekum,॥ \\ and $Q$. Zebeli*1 \\ ${ }^{*}$ Institute of Animal Nutrition and Functional Plant Compounds, Department for Farm Animals and Veterinary Public Health, \\ University of Veterinary Medicine Vienna, 1210 Vienna, Austria \\ †Institute of Veterinary Physiology, Freie Universität Berlin, 14163 Berlin, Germany \\ ‡Department of Animal Sciences and Industry, Kansas State University, Manhattan 66506 \\ $\S A n i m a l$ and Poultry Science, University of Saskatchewan, Saskatoon, Canada, S7N 5A8 \\ \#Department of Animal Science, Agriculture University of Tirana, Tirana 1000, Albania \\ IIInstitute of Animal Science, University of Bonn, 53115 Bonn, Germany
}

\begin{abstract}
Rumen health is of vital importance in ensuring healthy and efficient dairy cattle production. Current feeding programs for cattle recommend concentraterich diets to meet the high nutritional needs of cows during lactation and enhance cost-efficiency. These diets, however, can impair rumen health. The term "subacute ruminal acidosis" (SARA) is often used as a synonym for poor rumen health. In this review, we first describe the physiological demands of cattle for dietary physically effective fiber. We also provide background information on the importance of enhancing salivary secretions and short-chain fatty acid absorption across the stratified squamous epithelium of the rumen; thus, preventing the disruption of the ruminal acid-base balance, a process that paves the way for acidification of the rumen. On-farm evaluation of dietary fiber adequacy is challenging for both nutritionists and veterinarians; therefore, this review provides practical recommendations on how to evaluate the physical effectiveness of the diet based on differences in particle size distribution, fiber content, and the type of concentrate fed, both when the latter is part of total mixed ration and when it is supplemented in partial mixed rations. Besides considering the absolute amount of physically effective fiber and starch types in the diet, we highlight the role of several feeding management factors that affect rumen health and should be considered to control and mitigate SARA. Most importantly, transitional feeding to ensure gradual adaptation of the ruminal epithelium and microbiota; monitoring and careful management of particle size distribution; controlling feed sorting, meal size, and meal frequency; and paying
\end{abstract}

Received May 19, 2017.

Accepted September 28, 2017.

${ }^{1}$ Corresponding author: Qendrim.Zebeli@vetmeduni.ac.at special attention to primiparous cows are some of the feeding management tools that can help in sustaining rumen health in high-producing dairy herds. Supplementation of feed additives including yeast products, phytogenic compounds, and buffers may help attenuate SARA, especially during stress periods when the risk of a deficiency of physically effective fiber in the diet is high, such as during early lactation. However, the usage of feed additives cannot fully compensate for suboptimal feeding management.

Key words: dairy cow, ruminal $\mathrm{pH}$, subacute rumen acidosis, physically effective fiber

\section{INTRODUCTION}

Dairy cows have high nutritional demands during lactation. A common practice to meet these high requirements for energy and MP is to feed large quantities of concentrates, especially during early and mid lactation. Typically, grain-based high-starch concentrates are fed at the expense of high-fiber forages, thereby enhancing the energy density of the diet but also compromising physically effective fiber (peNDF) content of lactation diets. Physically effective fiber is needed in cattle diets to stimulate chewing activity and salivary buffer supply, rumen motility and mixing, and to maintain appropriate functioning of the rumen ecosystem (Allen, 1997; Zebeli et al., 2012). On the other hand, grain-rich concentrates are palatable and easily fermentable in the rumen. The rapid fermentation stimulates microbial growth but also generates large amounts of short-chain fatty acids (SCFA), especially glucogenic precursors, which are used by the host as metabolic fuels and precursors for synthesis of several metabolic compounds (Aschenbach et al., 2010).

Rapid production of SCFA relative to the buffer supply disrupts intraruminal acid-base regulation (Steele et al., 2011). Intermittent drops of ruminal $\mathrm{pH}$ 
(Dirksen, 1985) gradually affect rumen function and, if severe, long, and frequent enough, are designated as SARA. Due to mainly nonpathognomonic signs of SARA, controversy exists about its definition. The current guideline is that the risk of SARA increases when ruminal $\mathrm{pH}$ drops below 5.6 for more than $3 \mathrm{~h} / \mathrm{d}$ (Plaizier et al., 2008) or below 5.8 for more than 5 to 6 $\mathrm{h} / \mathrm{d}$ (Zebeli et al., 2008). Research in the last $10 \mathrm{yr}$ has established that dairy cattle suffering from SARA have greater risks of developing costly metabolic disorders such as displaced abomasum, fatty liver, laminitis, liver abscesses, and downer cow syndrome (Plaizier et al., 2008, 2012; Zebeli and Metzler-Zebeli, 2012). Collectively, it can be anticipated that the secondary disturbances have far-reaching consequences for cattle health and productivity (Plaizier et al., 2008, 2012; Zebeli and Metzler-Zebeli, 2012).

The causal relationships between current feeding strategies and incidence of SARA, as well as their consequences for rumen and host health, have been investigated intensively and the findings have been summarized in several comprehensive reviews (Plaizier et al., 2008, 2012; Steele et al., 2016). The results of this research have established the role of peNDF in the prevention of SARA in dairy cattle (Zebeli et al., 2012; GfE, 2014). The peNDF concept amalgamates the chemical (fiber) and physical (particle size) properties of the feed, providing a feasible tool for predicting physical effectiveness of a diet (i.e., when provided as TMR) under practical farm conditions. Besides the peNDF content in the diet, SARA incidence and severity depend on diet-related factors such as the amount and fermentability of starch fed and the feed intake level (Silveira et al., 2007; Zebeli et al., 2012). Feeding management factors are also crucially important in reducing the incidence of SARA. For example, the concept of TMR feeding ideally presumes simultaneous intake of forages and concentrates, thereby smoothing the daily fermentation pattern and avoiding periods of excessive fermentation activity. However, cattle commonly sort out the concentrates of their feed, resulting in an irregular and potentially inadequate peNDF intake, both when considering the intake profile of a given cow over the day and when considering feed sharing among cows of differing sorting efficiencies in a feeding cohort. This behavior is so common that the sorting and eating behaviors of cows have recently been emphasized by several researchers as strong causal factors of SARA (DeVries et al., 2008; Gao and Oba, 2014; Nasrollahi et al., 2017). As the extent of sorting depends on several management factors, large differences in the effects of sorting behavior may be expected among dairy farms with regards to SARA. Feeding management using TMR is commonly used on large dairy farms, and partial mixed ration (PMR) feeding is typically used on small and medium-sized farms, the latter with separate concentrate feeding in transponder feeding stations. Furthermore, the duration of adaptation to a new high-starch diet and the parity of the cows seem to play a role in the requirements for peNDF of cows to maintain ruminal $\mathrm{pH}$ within physiological ranges, thereby preventing SARA (Humer et al., 2015a; Pourazad et al., 2016). The main objective of this review is therefore to provide an overview of the practical methods available for assessing the adequacy of dietary fiber in dairy cow diets, as well as recommend practical feeding management guidelines to mitigate SARA in dairy herds.

\section{CHALLENGES TO REGULATE RUMINAL ACID-BASE BALANCE IN HIGH-PRODUCING DAIRY COWS}

Nutrition for high-producing cattle aims to maximize the conversion of high levels of dietary ingredients into metabolic fuels and substrates to meet the high nutritional demands of the cow. The carbohydrate fraction of ruminally fermentable organic matter (RFOM) in a typical dairy cow TMR containing grain-based concentrates is composed of approximately one-half fiber and one-half nonstructural carbohydrate, with most of the latter being in the form of starch. Ruminally fermentable OM supply is a key determinant of microbial protein yield (Lanzas et al., 2007), which is the predominant source of amino acids for the cow. Furthermore, the majority of fermentation and the most efficient fiber degradation in the ruminant occurs in the rumen, so if the cow is to derive sufficient energy from the $\geq 30 \%$ of the diet that is NDF, it needs to be fermented to SCFA in the rumen by microbes. However, the production rate of SCFA (primarily acetate, propionate, and butyrate) must not be allowed to exceed the ruminal capacity for uptake and buffering over a whole day, requiring a balancing act of feeding microbes without disrupting ruminal pH (Steele et al., 2011).

In many TMR, starch is a substantial contributor to RFOM supply. The site of starch digestion differs dramatically between types of grains (Patton et al., 2012) and processing methods (Owens, 2005; Humer and Zebeli, 2017). Dairy cow diets based on grains such as wheat or barley (and even rye), corn, and sorghum have mean ruminal starch degradation of 76,55 , and $54 \%$, respectively, based on a meta-analysis (Patton et al., 2012). These differences are decreased after postruminal digestion, with means of 95,92 , and $80 \%$, respectively, for total-tract digestibility, indicating a compensation of digestion postruminally. Wheat, rye, and corn have the highest total starch contents (Offner et al., 2003; Benninghoff et al., 2015). Processing effects are nearly 
as important as grain source. Dairy cow diets based on ensiled high-moisture corn, steam-processed corn, and dry-rolled corn had mean ruminal starch digestibilities of 76,54 , and $49 \%$, respectively (Owens, 2005), with total-tract digestibilities ranging from 90 to $96 \%$. Thus, changing processing methods makes it possible to shift more than $20 \%$ of intake starch from ruminal to postruminal digestion (Moharrery et al., 2014). Such approaches can then be used to decrease the load of starch fermentation in the rumen (Silveira et al., 2007) and modulate supply of RFOM while maintaining the supply of energy to the cow, or in some cases, increasing energy supply through greater feed intake (Bradford and Allen, 2007). However, due to the limited capacity of cattle to digest starch postruminally, constraints in the extent that starch digestion can be shifted from the rumen to the intestine have to be considered (Harmon et al., 2004). In this regard, increased quantities of starch reaching the large intestine enhance the risk of hindgut acidosis (Gressley et al., 2011; Plaizier et al., 2017). Besides shifting degradation of starch postruminally, an approach to lower RFOM fermentation load in the rumen while maintaining high energy density in the diet might be the addition of rumen-protected fat to dairy diets (Naik, 2013). However, there are limitations in the absolute amount of dietary fat provided to cows. The NRC (2001) recommends a maximum level of 6 to $7 \%$ fat in diet DM, and that it should consist of fat from natural feeds, oilseeds, and rumen-protected fat in 3 equal proportions (Naik, 2013). As such, considering the addition of a typical allowance of 200 to $500 \mathrm{~g} / \mathrm{d}$ of rumen-protected fat in the dairy diet, the potential of sparing RFOM from rumen fermentation may be limited to roughly $800 \mathrm{~g} / \mathrm{d}$ of RFOM. Taking into account the large amount of RFOM available in a dairy diet (>10 kg/d), this spared amount of RFOM might be not fully effective to mitigate SARA on its own.

Diets that supply relatively large quantities of RFOM $(\geq 10 \mathrm{~kg} / \mathrm{d}$; Allen, 1997; Shaver, 2002) result in the rapid production of SCFA and lactate, an intermediary metabolite of starch fermentation. Although evidence for limited absorption of lactate is increasing (Qumar et al., 2016), most of the produced lactate is further metabolized by lactate-utilizing microbes. The SCFA are absorbed, to the major extent, directly across the stratified squamous epithelium (SSE) of the rumen via diffusion and protein-mediated pathways, and then used as fuels or substrates by the host (Aschenbach et al., 2010, 2011). Host recovery of SCFA is an essential physiological process not only for overall efficiency of feed energy utilization but also for preventing acidification of the rumen contents (Gäbel et al., 2002; Penner et al., 2009). On the one hand, absorption of SCFA through rumen SSE ensures direct recovery of energy substrates and glucogenic precursors from the rumen into the metabolic pool of the animal. On the other hand, enhanced absorption facilitates the extraction of protons and the exchange of bicarbonate ions with luminal SCFA (Aschenbach et al., 2011), contributing to buffering of the rumen content. From both perspectives, it is of great interest to stimulate the protein-mediated uptake pathways and intracellular metabolism of SCFA of the rumen SSE and this remains a focus of intensive research (Penner et al., 2011; Schurmann et al., 2014; Steele et al., 2015). Compared with SCFA, lactate is a much stronger (acid dissociation content, $\mathrm{p} K_{\mathrm{a}}=3.9$ vs. 4.8 for SCFA; Cistola et al., 1982; Kohn and Dunlap, 1998) and more influential acid in the regulation of rumen acid-base balance. Although model studies in sheep identified negligible lactate transport activity in the apical membrane of SSE (Aschenbach et al., 2009) and ascribed lactate transport primarily to monocarboxylate transporter- 1 in the basolateral membrane (Müller et al., 2002), new studies in beef and dairy cattle indicate the ability of the rumen SSE to absorb small amounts of lactate during extended periods under acidic conditions (Schwaiger et al., 2013a; Qumar et al., 2016), most likely through SSE co-transport with its dissociated proton (Gäbel et al., 2002). Although this seems to be a short-term reaction of rumen SSE to decrease the acidic load during long-term grain-rich feeding in cows, there is also a notable adaptation of rumen SSE that is important for the recovery of SCFA and regulation of acid-base balance in cattle (Schwaiger et al., 2013a,b; Qumar et al., 2016).

The secretion of alkaline saliva is another indispensable physiological process for regulating the acid-base balance (Allen, 1997; Chibisa et al., 2016). Although SCFA absorption is the predominant mechanism to counteract the development of acidosis (Penner et al., 2009), salivary secretion is enforced after a bout of ruminal acidosis, likely to compensate for impaired SCFA absorption and buffering by the (damaged) ruminal SSE (Schwaiger et al., 2013a). Salivary secretion rates in high-yielding cattle breeds are quite impressive and reach values of $\sim 250 \mathrm{~L} / \mathrm{d}$ (Maekawa et al., 2002; Bowman et al., 2003; Jiang et al., 2017); however, feeding diets low in peNDF has been shown to linearly depress chewing activity (Zebeli et al., 2010). As the salivary flow rate during rumination and during eating is higher than that during resting (1.8 and 1.2 times, respectively), the decreased chewing activity causes a subsequent decrease of salivary buffer secretion, finally impairing ruminal pH (Cassida and Stokes, 1986; Kröger et al., 2017). As such, research must be done to develop feeding strategies that can stimulate chewing activity, and thereby salivary secretions, during intensive phases of rumen fermentation (Kröger et al., 2017). Modulation 
of eating and chewing behavior toward more time spent chewing will increase salivary buffers and stimulate more efficient neutralization of protons (Chibisa et al., 2016), thus helping to prevent over-acidification of the rumen content and development of SARA.

Although the primary role of peNDF is generally considered the stimulation of salivary secretion, increasing the peNDF content in the diet might also result in reduced diet digestibility and fermentability. In addition, rumen sensory receptor mechanisms stimulated by tactile stimulation of fiber particles or passive distention of the rumen would stimulate rumen motility (Zebeli et al., 2012). Storm and Kristensen (2010) suggested that the major barrier toward absorption of SCFA across SSE was movement of SCFA from the medial region of the rumen (rumen mat to rumen fluid interface) such that the SCFA come in contact with the rumen SSE. Blood flow is another regulator of SCFA absorption (Storm et al., 2012), and increasing peNDF should then result in greater blood flow associated with ruminal contractions. Thus, provision of adequate peNDF is required not only to stimulate salivary secretion but also for ruminal motility - that should promote SCFA absorption - and the separation and removal of fermentation gases to prevent bloat.

Consequently, optimum adaptation and recovery of SCFA across ruminal SSE (Penner et al., 2011) and effective salivary buffer secretion (Chibisa et al., 2016) are of central importance in maintaining optimal rumen $\mathrm{pH}$ and health.

\section{PREVALENCE OF SARA}

Failure to maintain an appropriate acid-base balance leads to intraruminal accumulation of protons and a subsequent drop in $\mathrm{pH}$ below the physiological range of about 6.0 to 7.0 , a condition commonly known as SARA (Krause and Oetzel, 2006; Plaizier et al., 2008; Zebeli et al., 2012). In general, 2 groups of cows are at high risk for SARA: cows during early lactation and those in the mid-lactation period. The former group undergoes a strong shift from a high-peNDF diet to an energy-dense diet in early lactation, which if carried out too abruptly will likely surpass the absorptive, metabolizing, and neutralization capacity of the ruminal SSE (Aschenbach et al., 2011). Because of the evidence that cows experiencing the first bout of SARA undergo more severe SARA after a recovery period of 3 (Dohme et al., 2008) to $7 \mathrm{~d}$ (Pourazad et al., 2016), it is feasible to suggest that mitigating SARA during early lactation will decrease the susceptibility of SARA later during the lactation. Humer et al. (2015b) observed strong and abrupt depression of ruminal $\mathrm{pH}$ from an average of 6.3 in the week before parturition to a daily mean $\mathrm{pH}$ of below 5.8 starting from d 6 postpartum in a group of cows having ad libitum access to a close-up diet without grains and offered increasing amounts of a fresh-lactation TMR with $47 \%$ concentrate. Interestingly, cows that voluntarily consumed larger $(P<0.05)$ amounts of the close-up diet during this postpartum period (5.2 vs. $2.4 \mathrm{~kg}$ of DM/d) did not experience ruminal $\mathrm{pH}$ drops and SARA conditions, despite similar $(P>0.05)$ intake of fresh lactation TMR $(6.4 \mathrm{vs} .7 .7$ $\mathrm{kg}$ of DM/d) as well as total DMI (11.5 vs. $10.0 \mathrm{~kg})$ in both groups of cows. Therefore, it can be speculated that the decreased chewing time due to lesser intake of the forage-rich close-up TMR contributed to the lower ruminal $\mathrm{pH}$ in the SARA-susceptible cows.

The diets fed during the last period of pregnancy (especially the far-off diet) are commonly high in forage and peNDF and contain little, if any, concentrates (starch), resulting in shorter papillae and a highly diverse ruminal microbiota composed of mainly cellulolytic bacteria (McCann et al., 2014; Steele et al., 2015; Dieho et al., 2017). The feeding of close-up diets during the last weeks before calving prepares the rumen and overall metabolic efficiency of the cow, including production and the quality of colostrum. This is commonly done by feeding forages of higher quality (which will be further fed during lactation) and moderate amounts of concentrates rich in starch, MP, and required minerals and vitamins. Although this approach could be expected to decrease the risk for SARA postpartum, there is evidence that feeding large amounts of concentrates (up to $54 \%$ vs. $46 \%$ of the diet DM) during far-off and close-up periods does not reduce the risk for ruminal acidosis postpartum in primiparous cows fed the same low fiber $(30 \% \mathrm{NDF})$ fresh-lactation diet (Penner et al., 2007). The lack of a protective effect of the "steam-up" close-up diet approach is likely due to a greater depression in DMI of cows fed grain-rich diets as parturition approaches than when diets higher in peNDF are fed (Hayirli et al., 2003; Rabelo et al., 2003). Low feed intake, even of diets considered to be of low risk for low ruminal $\mathrm{pH}$, followed by increased DMI can be used to induce ruminal acidosis (Albornoz et al., 2013; Zhang et al., 2013). Thus, depression of DMI before parturition and strong dietary transition from diets of nearly all forage to a highly fermentable diet (up to $60 \%$ concentrates), together with considerable stress in the peripartal period, put early-lactating cows at a high risk for developing SARA (Roche et al., 2013). The close-up diets obviously should aim for an improved appetite in periparturient cows. As reported by Humer et al. (2015b), feeding cows high-quality forage and limited amounts of concentrate $[2$ to $3 \mathrm{~kg} /($ cow $\cdot d)]$ counteract the limited feed intake of cows in the last weeks prepartum. Gradually increasing concentrates (by 0.25 
$\mathrm{kg}$ of $\mathrm{DM} / \mathrm{d}$ ) postpartum has been shown to provide a better adaptation of rumen microbiota during the first $30 \mathrm{~d}$ of lactation than increasing the daily concentrate allowance by $1 \mathrm{~kg}$ DM of concentrate [up to $10 \mathrm{~kg}$ of $\mathrm{DM} /(\mathrm{cow} \cdot \mathrm{d})$; Dieho et al., 2017]. Considering that concentrates fed in that study were rich in by-products and thus low in starch (25\% starch), gradual adaptation may be even more important with the high-starch/lowfiber concentrates that are commonly used in TMR-fed transition cows. Indeed, farmers using TMR feed only a few variants of lactation diets and, therefore, freshlactating cows are often confronted during the second week of lactation with an abrupt increase of energy (i.e., starch) content with almost 40 to $50 \%$ concentrates on DM basis, instead of being adapted gradually. Furthermore, the ingestion of concentrates is often higher than formulated, because cows generally sort concentrates out of component feeding (Nocek, 1997; Kleen et al., 2003). This situation may be exacerbated when using automated milking systems (AMS), because a greater quantity of concentrate is often provided for cows with high or increasing milk yield without considering the effect that the increased concentrate allocation has on PMR intake and ruminal fermentation.

In the literature, even higher incidences of SARA have been reported, based on ruminocentesis, in midlactating cows (Nordlund et al., 1995; Stone, 2004). However, DMI is highest during mid lactation, which potentiates other predisposing factors (Nordlund et al., 1995; Stone, 2004) and indicates that the development of SARA in mid-lactation cows is primarily linked to management factors such as formulation of diets beyond general recommendations regarding the content of ruminally fermentable starch and peNDF, low feeding frequency, excessive processing of feed (Nordlund et al., 1995; Oetzel, 2000), eating of large meals ( $4 \mathrm{~kg} /$ meal) during the day (Erickson et al., 2003; Macmillan et al., 2017), or excessive diet sorting in favor of concentrates, especially during the first $6 \mathrm{~h}$ after the morning feeding (Nasrollahi et al., 2017). In a recent study, Macmillan et al. (2017) observed that cows at higher risk of SARA (based on an index taking into account the area below $\mathrm{pH} 5.8$ related to DMI) spent more time eating in the first 8-h period after feeding than lower-risk cows (186 vs. $153 \mathrm{~min}$ ) and less time eating in the third 8-h period (19 vs. $43 \mathrm{~min}$ ) of the day.

In herds fed a component-based diet, the time schedule of feeding should aim to feed smaller proportions of concentrate more frequently (Nordlund et al., 1995; Kleen et al., 2003). In TMR feeding systems, access to feedstuffs is important. If access is limited, socially dominant cows will eat first and for longer, especially in larger groups with limited bunk access. These cows then have more opportunity to sort the feed, to select for concentrates, and to suffer from SARA (Kleen et al., 2003).

\section{MEASURING THE PHYSICAL EFFECTIVENESS OF DIETS}

Physical effectiveness is the ability of a dairy diet to maintain chewing activity and rumen health. This is primarily determined by fiber content and particle size, and by the amount of ruminally digestible carbohydrate intake, especially starch, per unit of time (Zebeli et al., 2012). It is generally agreed that both the amount and the physical form of dietary fiber play a fundamental role in dairy cow nutrition (Beauchemin and Yang, 2005). Specifically, long fiber particles enable the maintenance of a thick-packed ruminal mat, which acts as a particle sorting system (filter bed effect), stimulates rumen contractions, promotes mixing of the digesta and SCFA absorption, while also regulating the passage of digesta (Tafaj et al., 2004; Zebeli et al., 2012). Lack of clear stratification of digesta in the rumen suggests impaired rumen conditions and fiber deficiency. A reduction in the consistency of the ruminal mat (Yang et al., 2002) thereby reduces the entrapment of medium feed particles (Poppi et al., 2001) and increases the outflow rate of solid digesta, which results in impaired ruminal fiber digestibility (Boddugari et al., 2001; Tafaj et al., 2004).

Neutral detergent fiber consists of hemicellulose, cellulose, and lignin fraction of feeds (Van Soest, 1967) and, when corrected for ash content, it is the preferred estimate of fiber content of the diet (Coppock, 1987; Varga et al., 1998). The NRC (2001) recommends that NDF should be maintained at least at $25 \%$ (in diets containing ground corn as the predominant starch source) of dietary DM, which is a very low value, considering that this amount of NDF can also be provided via concentrates. Furthermore, as the NDF content of a diet only provides information about its chemical characteristics, it is not sufficient for assessing fiber adequacy in ruminant diets. Because it combines physical and chemical characteristics, the concept of peNDF has become widely accepted (Mertens, 1997). The peNDF concept takes into account the physical properties of the fiber (primarily particle size). However, expression and characterization of the particle size of forages or diets is difficult, and using forages with large particles does not necessarily mean the diet fed to or consumed by cows still contains large particles (reviewed by Zebeli et al., 2012). Therefore, analyzing the distribution of particle fractions of the diet and orts is more advantageous and accurate to express the particle size of the consumed 
diet, than considering the theoretical length of the cut (TLC) or measuring the mean particle length of forages. A widely accepted method to measure particle size is the Penn State Particle Separator (PSPS) - it allows a quick and practical method for routine use under on-farm conditions of the distribution of the particle fractions of the original mixed diets and their orts without the need for drying (Lammers et al., 1996).

The PSPS typically contains 3 sieves that enable the determination of 4 fractions: particles retained on a 19-mm sieve (large particles), proportion of particles that pass through the $19-\mathrm{mm}$ sieve but are retained on the $8-\mathrm{mm}$ sieve (medium particles), and proportion of particles that pass through the 8 -mm sieve but are retained on the $1.18-\mathrm{mm}$ sieve (fine particles), and the particles that pass completely through (very fine particles; Lammers et al., 1996; Kononoff et al., 2003). After weighing the fractions of the feed retained on each sieve and calculating their percentages, it is possible to understand the distribution of particles of a specific diet. By measuring the particle distribution of the orts several times throughout the day and comparing it with particle distribution of the diet, a veterinarian or nutritionist is able to quantify the sorting of the diet within a day (Nasrollahi et al., 2017). Using the percentage of particles retained on different screens, the physical effectiveness factor (pef) either with particles $>8$ (pef $>8$ ) or $>1.18$ (pef $>1.18$ ) $\mathrm{mm}$ in length can be calculated (Lammers et al., 1996; Kononoff et al., 2003). Without taking into account the NDF content of the diet, the pef of any size is not enough to describe physically effectiveness of the diet. The peNDF can be determined as peNDF $>8$ and peNDF $>1.18$ (Lammers et al., 1996; Kononoff et al., 2003). Although both peNDF measurements are appropriate for TMR containing mealy or powdered concentrate sources, peNDF $>8$ is more accurate for TMR using pelleted concentrates because pelleted feeds are totally retained on the 1.18$\mathrm{mm}$ sieve, which is a misinterpretation because the pellets comprise very fine particles that would mostly pass through the 1.18-mm sieve. Because the pellet will crumble and dissolve in the mouth or rumen without chewing, the pef of the dry pellet is not an accurate representation of peNDF in the rumen.

\section{PRACTICAL FEEDING GUIDELINES TO MITIGATE SARA}

\section{Adequate Dietary Adaptation}

Dairy farmers, veterinarians, and nutritionists must carefully consider the major challenge of the modern dairy-nutrition strategy, which aims to fulfil a cow's high nutritional needs and, concomitantly, meet the requirements of a healthy rumen ecosystem. The feeding management principles for mitigating SARA should aim to alleviate the high acidic load in the rumen to help maintain acid-base regulation so that the production of SCFA does not result in a surplus of protons, paving the way to rumen acidification and SARA (Aschenbach et al., 2011). In this context, the feeding of high-producing cows should target adaptation of the rumen SSE and the microbiome to the large amounts of ruminally degradable starch (RDS) and other RFOM eaten daily such that the balance between production and absorption of SCFA can be maintained (Kleen et al., 2003). This adaptation is particularly important during transition from the close-up to the early-lactation diet and in phases of increases of feed intake of cows during mid lactation.

It is currently believed that the ruminal SSE takes 4 to 6 wk to adapt to concentrate-rich diets, by increasing the absorptive area as well as its functional capacity to cope with the sudden increase of SCFA levels (Bannink et al., 2012; Dieho et al., 2016), whereas the microbiological changes, such as the shift from cellulose degraders such as Fibrobacter and Ruminococcaceae to mainly starch-fermenting taxa such as Prevotella, are said to take place within $3 \mathrm{wk}$ (Dieho et al., 2016, 2017; Wetzels et al., 2017). As shown in Figure 1, recent studies conducted by our team have revealed that adaptation to a high-grain diet led to improved SCFA absorption and this effect was reflected by improved $\mathrm{pH}$ dynamics when the high-concentrate diet was fed for 4 to 5 wk continuously. On the other hand, interrupting concentrate feeding after the second week stopped these adaptive processes (Pourazad et al., 2016; Qumar et al., 2016). Thus, an adaptation period of at least 4 to 5 wk of concentrate feeding and consistency in feeding seem to be of utmost importance in terms of rumen adaptation and SARA prevention.

\section{Primiparous Versus Multiparous Cows}

In general, SARA susceptibility might also be influenced by parity. Primiparous cows seem to be at higher risk than multiparous cows (Krause and Oetzel, 2006; Bramley et al., 2008), which requires special feeding management strategies for primiparous cows. As depicted in Figure 2, Humer et al. (2015a) observed shorter periods in which reticular $\mathrm{pH}$ dropped below 6.0 in multiparous cows compared with primiparous cows fed the same lactation diet from d 20 to 80 postpartum. This may be due to several reasons. First, multiparous cows have already experienced high-grain diets, whereas first-lactation heifers are typically fed 

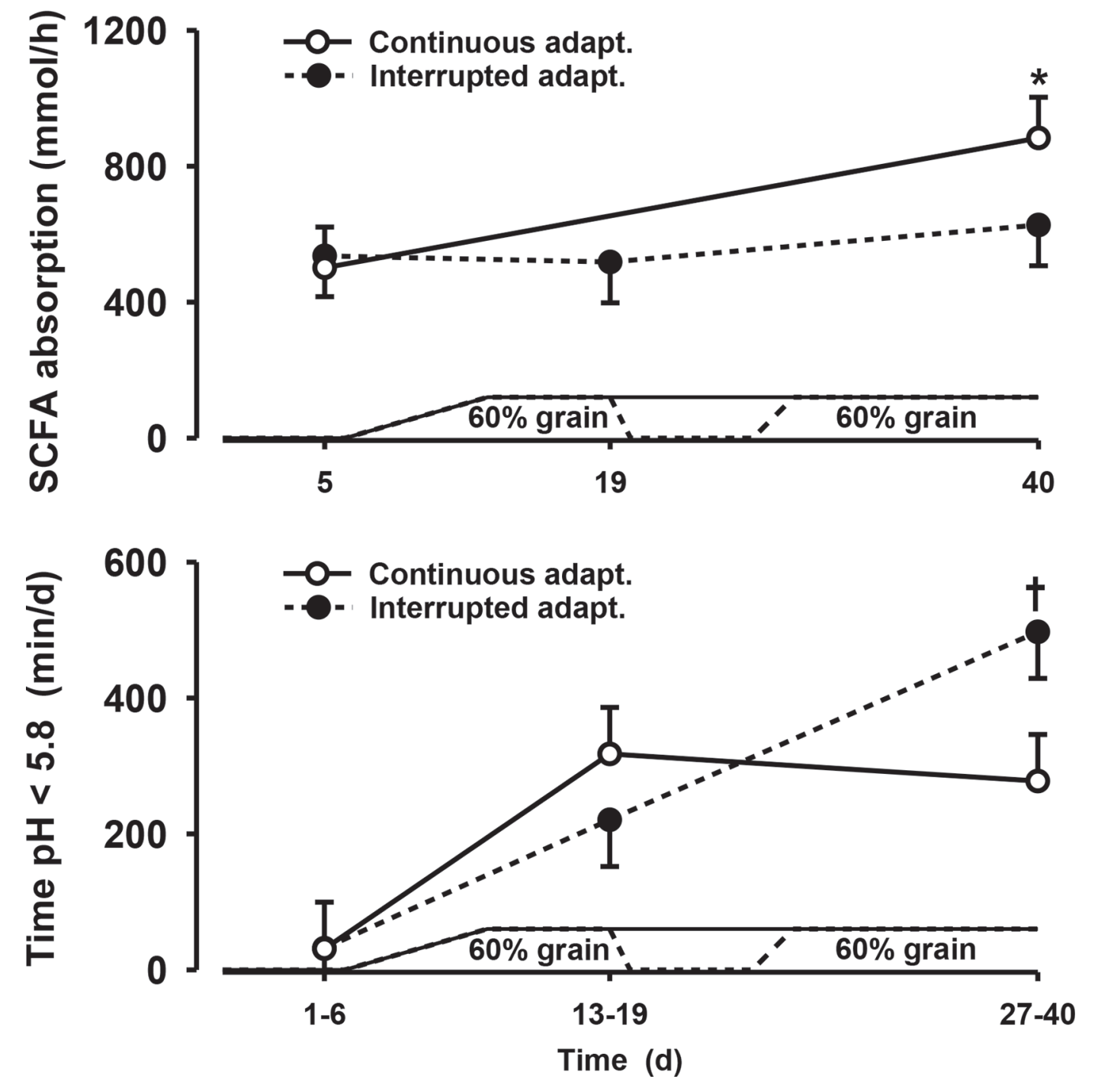

Figure 1. Absorption of short-chain fatty acids (SCFA) and time of reticular pH below 5.8 in dairy cows adapted to a high grain diet either continuously (Continuous adapt.) or interrupted by a 1-wk pure roughage feeding (Interrupted adapt.), $*$ and $\dagger$ indicate differences at $P<0.05$ and $P<0.01$, respectively, between interrupted and continuous feeding (adapted from the studies by Pourazad et al., 2016; Qumar et al., 2016). Error bars indicate SEM.

high levels of energy-dense feeds the first time since their transition to a functioning ruminant after weaning. Thus, heifers are assumed to have fewer rumen papillae and a less-adapted rumen microbiome (Penner et al., 2007; Bramley et al., 2008). Second, different chewing behaviors between parities might exist, with heifers having lower chewing time, hence reducing output of salivary buffers (Maekawa et al., 2002; Bowman et al., 2003). Third, first-lactation heifers might differ in their feeding behavior, especially when older and socially higher cows are present in the same lactation group; therefore, they might have difficulty getting access to the feeders for small, more frequent meals
(Krause and Oetzel, 2006). Increased feeding frequency has been related to lesser severity of SARA (Macmillan et al., 2017). Also, differences in BW, and hence rumen volume, might play a role in susceptibility to SARA. A recent study by Nasrollahi et al. (2017) noted that SARA-susceptible cows were, on average, $50 \mathrm{~kg}$ lighter than SARA-tolerant cows. Finally, heifers might also include cows that are unable to learn to self-regulate their ruminal pH (Oetzel, 2007). Although some studies observed no differences among parities (Gröhn and Bruss, 1990) or even opposite trends (Maekawa et al., 2002), most studies point to a higher risk of SARA in first-lactation cows than in multiparous cows. There- 
fore, more care should be taken in the feeding management practices of this group of cows, especially during early and mid lactation.

\section{Specifics in Farms Feeding TMR}

Besides the differences in feeding management practices mentioned above, there is a difference in estimating the physical effectiveness of the cow's diet in relation to SARA. The classical form of TMR is commonly formulated for production groups (not the individual cow), thereby enabling a relatively easy evaluation of the peNDF content of that TMR, as no additional concentrate is given individually to the cows (Zebeli and Humer, 2016a). However, the production groups typically contain large numbers of cows offered the same TMR, and the chances for feed sorting are high, especially when the TMR is not homogeneous $(>10 \%$ differences between samples sieved along the bunk feed; Carta, 2010) or feeding space is limited (DeVries et al., 2004).

In terms of estimating physical effectiveness of the TMR, both peNDF $>8$ and peNDF $>1.18$ can be used but peNDF $>8$ is preferred when concentrates in TMR are provided in a pelleted form (Zebeli and Humer, 2016a) or high amounts ( $\geq 15 \%$ of diet DM) of nonforage fiber sources, rich in fiber but of fine particle size, such as distillers grains with solubles, bran commodities, pressed beet pulp products, or brewers spent grains, are included (Bradford and Mullins, 2012). Table 1 outlines the recommendations regarding peNDF $>1.18$ contents needed to mitigate SARA in cows depending on the DMI level and the content of RDS of the diet. The higher the DMI and RDS, the greater the amount of peNDF $>1.18$ needed to prevent ruminal $\mathrm{pH}$ decline. However, it is important to note that peNDF $>1.18$ levels above $32 \%$ likely limit the DMI of cows (Zebeli et al., 2008). Therefore, feeding excessive amounts of RDS ( $\geq 16 \%$ of DM) should be avoided, especially when DMI potential is high $(\geq 22 \mathrm{~kg}$ of $\mathrm{DM} / \mathrm{d})$. In this regard, as described in the previous section, the amount of RDS differs significantly between cereals, with corn and sorghum being about 30 percentage units lower in RDS than barley, triticale, rye, or wheat (Offner et al., 2003; Benninghoff et al., 2015). Thus, grains with lower amounts of RDS, such as corn or sorghum, are the grains of choice to lower the risk of rumen fermentation disorders, especially during early lactation feeding. Moreover, the higher amount of starch that bypasses the rumen in low RDS cereals can then be utilized more

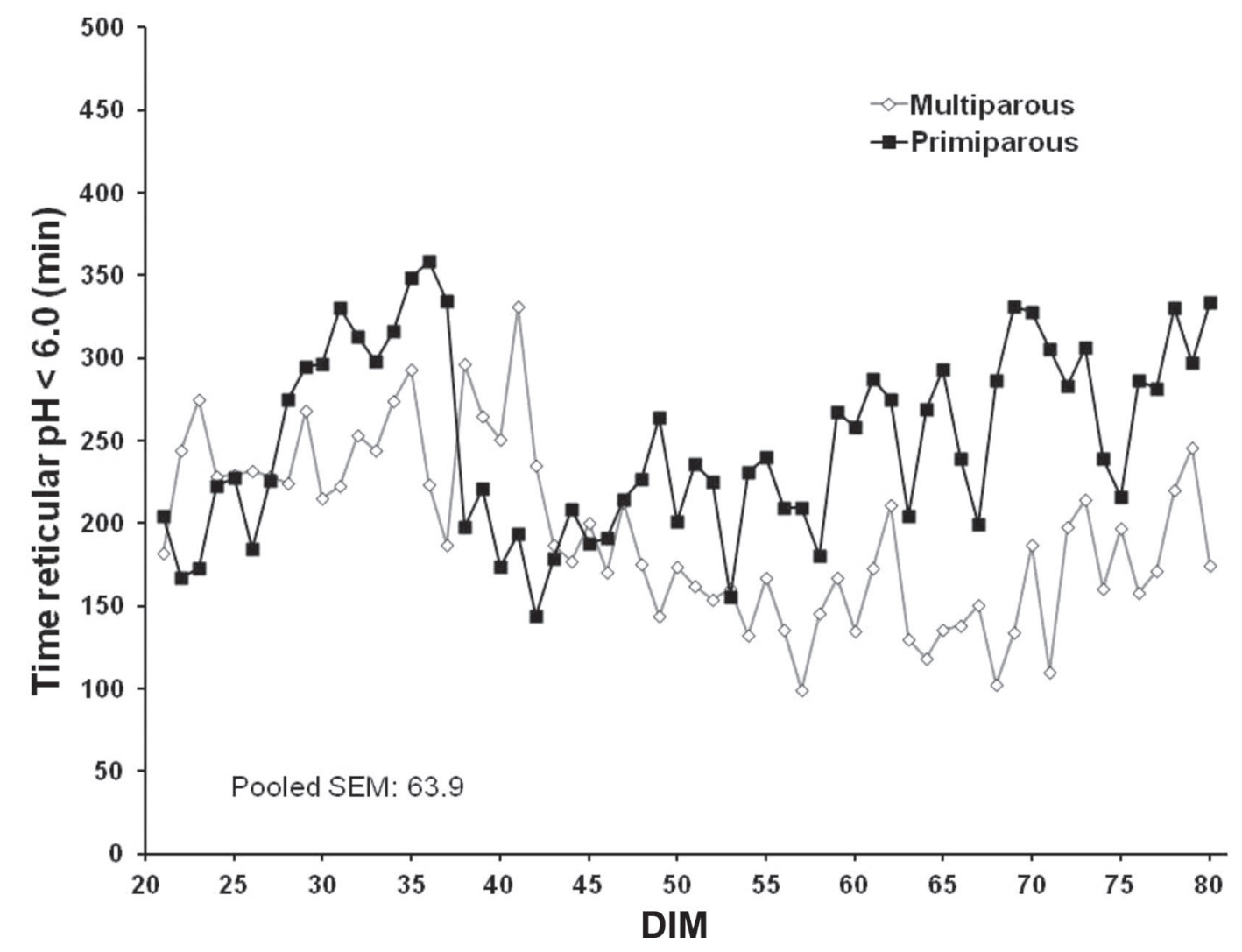

Figure 2. The duration of reticular pH below 6.0 in multiparous and primiparous dairy cows (adapted from Humer et al., 2015a). 
Table 1. Recommendations of the amounts of physically effective fiber inclusive of particles $>1.18 \mathrm{~mm}$ (peNDF $>1.18 ; \%$ of DM) in the diet of dairy cows with varying contents of ruminally degradable starch from grains (RDS) and DMI (adapted from GfE, 2014) ${ }^{1}$

\begin{tabular}{lcccc}
\hline & \multicolumn{4}{c}{ DMI level $(\mathrm{kg} / \mathrm{d})$} \\
\cline { 2 - 5 } RDS (\% of DM) & 18 & 20 & 22 & 24 \\
\hline 8 & 18 & 20 & 21 & 23 \\
12 & 21 & 23 & 25 & 28 \\
16 & 25 & 28 & 32 & $>32^{2}$ \\
20 & 32 & $>32^{2}$ & $>32^{2}$ & $>32^{2}$ \\
\hline
\end{tabular}

${ }^{1}$ The recommendation was derived using a ruminal $\mathrm{pH}$ value of 6.2 with the following equation: Ruminal $\mathrm{pH}=6.05+0.044 \times \mathrm{X}_{\mathrm{i}}-$ $0.0006 \times \mathrm{X}_{1}^{2}-0.017 \times \mathrm{X}_{2}-0.016 \times \mathrm{X}_{3}$, where $\mathrm{X}_{1}=$ peNDF $>1.18$ (\% of DM), $\mathrm{X}_{2}=\mathrm{RDS}$ from grains in the $\operatorname{diet}\left(\%\right.$ of DM), $\mathrm{X}_{3}=\mathrm{DMI}$ $(\mathrm{kg} / \mathrm{d})$; root mean squared error $=0.11, \mathrm{R}^{2}=0.66$ and $P<0.001$ (Zebeli et al., 2008).

${ }^{2}$ peNDF $>1.18$ contents of $>32 \%$ may limit DMI potential of the cows, so that the expected DMI level may not be reached.

efficiently in the duodenum, thereby improving the energy status of the cow (Matthé et al., 2001).

In addition to optimizing the amount of peNDF and RDS in the diet, providing enough eating space, avoiding stress, and preparing a homogeneous TMR with the goal to minimize selective feed consumption and encourage the intake of small and frequent meals are instrumental for SARA prevention (Zebeli and Humer, 2016b). In general, cows tend to select for the grain component and discriminate against the longer forage components, even when the feed is provided as a TMR (Leonardi and Armentano, 2003). Therefore, care must be taken with feeding management and the general distribution of particle size in the TMR, as these affect the feasibility of sorting and the feeding behavior of dairy cows. Recommendations for the distribution of particle size of TMR differing in the form of concentrates are summarized in Table 2 (partly adapted from Heinrichs and Kononoff, 2002).

It is obvious that the major part of particles (80-90\% of particles) in the TMR should be between 1.18 and $19 \mathrm{~mm}$, with medium and fine particle fractions being equally represented when ground concentrates are fed (Heinrichs and Kononoff, 2002). When pelleted concentrates are fed, the proportion of fine particles (i.e., $1.18-8 \mathrm{~mm}$ ) will be somewhat higher than particles between 8 and $19 \mathrm{~mm}$ because the pelleted concentrates cannot pass the 1.18-mm sieve. Only a small amount of particles $>19 \mathrm{~mm}$ or $<1.18 \mathrm{~mm}$ should be contained in the TMR (Heinrichs and Kononoff, 2002). This distribution is of paramount importance as a high percentage of particles $>19 \mathrm{~mm}$ lowers the homogeneity of the TMR and enables feed sorting against the longer forage components. As cows tend to sort small concentrate particles out of the diet, an inappropriate distribution of particle sizes enables cows to ingest a higher amount of RFOM than planned (Kleen et al., 2003; Dohme et al., 2008). As sorting of a TMR reduces the nutritive value of the TMR remaining in the feed bunk, this may be particularly detrimental for subordinate cows that have access to the feed only after dominant cows had their meal; that is, subordinate cows may be at risk to suffer from nutrient deficiency (DeVries and von Keyserlingk, 2005; Hosseinkhani et al., 2008). In this regard, it is also important to deliver feed frequently enough (about 2 to 4 times daily) because the act of feed delivery is the primary stimulus by which dairy cows are attracted to the feed bunk (DeVries and von Keyserlingk, 2005; DeVries et al., 2005; Macmillan et al., 2017). Higher frequencies of feed delivery and pushup not only reduce the amount of feed sorting but also enhance the ability of cows to access feed and the total time spent eating, and result in a more even distribution of feeding time throughout the day (DeVries et al., 2005). Thus, frequent feed delivery promotes more stable rumen fermentation conditions (González et al., 2012; Macmillan et al., 2017) as well as a more balanced nutrient intake, especially in TMR-feeding farms.

In recent years, a method of harvesting whole-plant corn silage, shredlage, has gained increasing interest as a potential way to enhance peNDF while concomitantly increasing kernel processing. Shredlage is corn silage produced with a harvester set for a longer TLC (up to $30 \mathrm{~mm}$ ) than commonly used (the conventional TLC of corn silage is set at about $6-10 \mathrm{~mm}$ ) and fitted with cross-grooved crop-processing rolls (Seglar and Shaver, 2014). Using this technology, the increased TLC (from 6 to $10 \mathrm{~mm}$ ) up to 26 to $30 \mathrm{~mm}$ enhances the proportion of long stover particles in the corn silage, thereby increasing the particle fraction $>19 \mathrm{~mm}$

Table 2. Recommendations for TMR particle size distribution when the TMR is composed of ground concentrates (TMR 1), with pelleted concentrates (TMR 2) or the diet is offered as partial mixed ration (PMR) (partly adapted from Heinrichs and Kononoff, 2002)

\begin{tabular}{llccc}
\hline Particle fraction & Screen size & TMR 1 (\%) & TMR 2 (\%) & PMR (\%) \\
\hline Large particles & $>19 \mathrm{~mm}$ & $3-8$ & $3-8$ & $15-25$ \\
Medium particles & $8-19 \mathrm{~mm}$ & $30-40$ & $35-45$ & $35-65$ \\
Fine particles & $1.18-8 \mathrm{~mm}$ & $30-40$ & $40-50$ & $15-25$ \\
Very fine particles & $<1.18 \mathrm{~mm}$ & $<20$ & $<10$ & $<8$ \\
\hline
\end{tabular}


in the TMR (from, on average, 5 to $17 \%$ ). However, studies have shown that this increase in the portion of large particles (i.e., $>19 \mathrm{~mm}$ ) occurs at the expense of medium particles (i.e., 8-19 $\mathrm{mm}$; decrease on average from 61 to $46 \%$ ), whereas the other particle fractions did not differ, ultimately leading to similar peNDF $>8$ and peNDF $>1.18$ amounts of the TMR (Ferraretto and Shaver, 2012; Vanderwerff et al., 2015). Thus, the inclusion of shredlage to reduce the risk of SARA is rather questionable, as this shift in large particles might impair the uniformity of the TMR, increasing the sorting against large particles and in favor of fine particles. Furthermore, enhanced ruminal starch digestibility due to the greater kernel breakage during harvesting (Ferraretto and Shaver, 2012) has to be considered. Indeed, no improvement in milk fat content or rumination activity has been observed in cows fed TMR containing shredlage compared with conventionally processed corn silage with short particle length, whereas improved starch digestibility and a tendency for higher milk yield were found (Ferraretto and Shaver, 2012; Vanderwerff et al., 2015).

\section{Specifics in Farms Using Separate Feeding}

Because of smaller numbers of the cows on small and medium-sized dairy operations (20 to $\sim 60$ cows/farm), the feeding of ingredients as TMR to separate production groups is generally not feasible. Consequently, these farms have adapted a PMR feeding practice. The PMR contains forages mixed in a mixing wagon with small amounts of concentrates $(\sim 2-3 \mathrm{~kg}$ per cow and day), typically consisting of grains, industrial by-products, and mineral and vitamin supplements (Bargo et al., 2002; Vibart et al., 2008) that are used to upgrade the PMR. The PMR is typically designed to be high in peNDF and meet the energy and nutrient requirements for maintenance plus a moderate level of milk production $(18-23 \mathrm{~kg} / \mathrm{d})$. As such, the same PMR is offered ad libitum to all lactating cows of the herd regardless of their phase of lactation and nutritive needs. In addition to having access to the PMR, each cow, receives varying amounts of concentrates, based on individual milk production and BCS, separately via computerized concentrate feeders $(\sim 0.4-0.5 \mathrm{~kg}$ of concentrate per each additional kilogram of milk produced; Hills et al., 2015). The concentrates fed in transponder feeding stations are usually commercially produced, mostly in pelleted form, and are variable in energy (starch), MP, minerals, and vitamins to support requirements for extra milk production that are not covered from the PMR intake. In addition to small and mediumsized farms, dairy operations using AMS also typically provide PMR, because high amounts of concentrates (up to $8 \mathrm{~kg} / \mathrm{d}$ ) are commonly offered in the AMS to improve milking attendance (Bach et al., 2007).

From the perspective of determining dietary fiber adequacy and risk of SARA, PMR feeding has similarities but also substantial differences compared with TMR feeding, which need to be taken into account by veterinarians and nutritionists. Similarly to TMR feeding, a uniform particle distribution is important to maintain uniform intake of PMR; to prevent sorting for concentrates and corn silage, such as broken kernels of corn silage, and against less palatable forages such as hay, straw, or grass silage; and to stimulate the intake of PMR (Zebeli and Humer, 2016a). The recommended distribution of particle size in the PMR is shown in Table 2, with particles between 8 and $19 \mathrm{~mm}$ making up the majority of the PMR. A proportion of particles $>19 \mathrm{~mm}$ in the diet higher than that indicated in Table 2 should be avoided to prevent PMR sorting, decreases in PMR intake, and decreases in the absolute intake of peNDF. The PSPS device can be used to check the uniformity of intake by comparing the particle distribution of the original PMR with that in orts. However, it should be noted that guidelines for a PMR are much more difficult to establish due to differing target nutrient densities in the PMR and differing amounts of concentrate allocated (Zebeli and Humer, 2016a).

To estimate fiber adequacy in PMR feeding systems, only the peNDF $>8$ system is recommended. Table 3 indicates the amount of peNDF $>8$ needed to avoid SARA, which is strongly dependent on the total starch content of the diet as well as the total amount of substrate ingested (i.e., DMI). Again, excessive amounts of peNDF (i.e., $>18 \%$ of peNDF $>8$ ) result in lowered maximal feed intake of the cow and should therefore be avoided. The estimation of fiber adequacy of the overall diet fed to a cow is more difficult under this feeding system. Most importantly, it is important to consider the additional concentrates provided via computerized concentrate feeders or AMS. This additional concentrate feeding has a direct effect on the calculation of the peNDF of the overall diet fed to the cow daily, especially when high concentrate allocations are provided. Most importantly, the additional concentrates fed shift the distribution of particles and the content of fiber of the overall diet. Specifically, for each $1 \mathrm{~kg}$ of concentrate provided via transponder feeding stations or AMS, approximately $2 \%$ of particles from the fraction $>19 \mathrm{~mm}$ has to be subtracted, and this percentage must be added to the fraction of particles $<8 \mathrm{~mm}$ (Zebeli and Humer, 2016a). This means that for a cow eating $6 \mathrm{~kg} / \mathrm{d}$ of concentrates via concentrate feeders or AMS, the fraction $>19 \mathrm{~mm}$ becomes $12 \%$ less, whereas 
the fraction of particles $<8 \mathrm{~mm}$ increases by $12 \%$. The same is true for the NDF content of the overall diet. Supplemental concentrates will lower overall NDF intake. Therefore, the NDF content of supplemental concentrates should be taken into account to estimate the overall NDF and peNDF $>8$ content (Zebeli and Humer, 2016a). Thus, the change in the particle size distribution has to be taken into account, together with the NDF content of the concentrates fed when calculating the peNDF $>8$ content of the overall diet fed to the cow daily. Furthermore, for each $1 \mathrm{~kg}$ of concentrates offered separately via concentrate feeders or AMS, cows will reduce the intake of PMR, thereby reducing the overall peNDF $>8$ intake. Although an exact calculation of the displacement of PMR due to separate concentrate intake is hard to do under on-farm conditions, data suggest that this displacement can vary between 0.3 and $1 \mathrm{~kg}$ of DM forage (depending on the forage quality and overall quality of PMR) for each $1 \mathrm{~kg}$ DM of concentrate fed via transponder feeding stations or AMS (Faverdin et al., 1991; Gruber et al., 2006; Bach et al., 2007; Vibart et al., 2008; Ho et al., 2013). In general, the DMI of forages and PMR, and thus their displacement, depends largely on their quality. For instance, to improve the intake of silages and PMR, appropriate fermentation characteristics (i.e., timely cutting date, restricted fermentation combined with low concentrations of acetic acid) are instrumental (Dulphy and Van Os, 1996; Südekum et al., 2016). The characteristics and production of high-quality forages have been analyzed in several previous reviews that are recommended as extended reading here (e.g., Charmley, 2001; Lüscher et al., 2014; Khan et al., 2015; Südekum et al., 2016). Large quality differences can be observed with hay. High-quality hay with a high content of watersoluble carbohydrates and little water-soluble protein can trigger appreciable DM and NDF intakes, replacing inclusion of large amounts of concentrates (Kleefisch et al., 2017). Besides reducing concentrate displacement, high-quality forage positively affects digesta stratification and turnover in the rumen, stimulating chewing activity (Tafaj et al., 2004, 2005). Thus, providing high-quality forages is also expected to mitigate the SARA risk. Indeed, a meta-analysis derived from 33 experiments pinpoints a positive relationship of forage quality (indicated by the amount of RFOM of forage) with the ruminal $\mathrm{pH}$ (Zebeli et al., 2006).

Overall, it is advisable to improve both the uniformity and the quality of the PMR to decrease its displacement and mitigate the SARA risk. Nevertheless, inaccuracy in the displacement size estimation of PMR increases the inaccuracy in estimating cows' peNDF $>8$ requirement in this feeding system.

\section{General Feeding Management}

Regardless of the feeding system, providing sufficient space at the feeding lane (at least $60 \mathrm{~cm} / \mathrm{cow}$; Rioja-Lang et al., 2012) is paramount. The provision of sufficient feed bunk space is necessary to reduce competition at the feed bunk and increase feeding activity (DeVries et al., 2004; Huzzey et al., 2006; Rioja-Lang et al., 2012), thereby improving access of cows to the offered feed and lowering the meal size of cows. Avoiding feed competition and improving feeding activity by allowing more feeding space might be especially important in fresh-lactation cows in which the first-lactation heifers might benefit from more feeding space, eating more uniform TMR and avoiding large meals.

An additional aspect in preventing feed sorting is appropriate mixing of the TMR. In TMR-fed herds, the ration should be mixed for only a few minutes (3 to 5 min after the last ingredient is added; Oelberg and Stone, 2014). Over-mixing of the ration produces a diet that will be easily taken up by the cows but that is very low in structure when mixers also have feed cutting capacity. A rapid rate of feed intake of a diet low in physical structure does not stimulate the necessary saliva flow, thereby reducing the buffering capacity of the feedstuffs (Nordlund et al., 1995; Kleen et al., 2003). Additionally, adding water to a dry TMR until a DM content of $<55 \%$ is reached, especially when dry forages are included in the ration, likely reduces feed selection, as it helps to bind particles together (Leonardi et al., 2005; Krause and Oetzel, 2006). With feeding technology of compact TMR, the homogeneity of the TMR is improved so that feed sorting is minimized. This concept aims at mixing the feed so completely that the fibers are shredded, which allows concentrates to mix

Table 3. Recommendations of the amounts of physically effective fiber inclusive of particle $>8 \mathrm{~mm}$ (peNDF $>8 ; \%$ of DM) in the diet of dairy cows with varying amounts of total starch and DMI (adapted from GfE, 2014) ${ }^{1}$

\begin{tabular}{lcccc}
\hline & \multicolumn{4}{c}{ DMI level $(\mathrm{kg} / \mathrm{d})$} \\
\cline { 2 - 5 } Total starch (\% of DM) & 18 & 20 & 22 & 24 \\
\hline 14 & 12 & 13 & 15 & 16 \\
18 & 14 & 15 & 17 & 18 \\
22 & 16 & 17 & $19^{2}$ & $21^{2}$ \\
26 & 18 & $20^{2}$ & $22^{2}$ & $22^{2}$ \\
\hline
\end{tabular}

${ }^{1}$ The recommendation was derived using a ruminal $\mathrm{pH}$ value of 6.2 based on the following equation: Ruminal $\mathrm{pH}=6.19+0.0438 \times$ $\mathrm{X}_{1}-0.000847 \times \mathrm{X}_{1}^{2}-0.00928 \times \mathrm{X}_{2}-0.01341 \times \mathrm{X}_{3}$, where $\mathrm{X}_{1}=$ peNDF $>8$ (\% of DM), $X_{2}=$ total starch content in the diet $(\%$ of $\mathrm{DM}), \mathrm{X}_{3}=\mathrm{DMI}(\mathrm{kg} / \mathrm{d})$; root mean squared error $=0.11, \mathrm{R}^{2}=0.65$, $P<0.001$ (Zebeli et al., 2010).

${ }^{2}$ peNDF $>8$ contents of $>18 \%$ may limit DMI potential of cows, so that the expected DMI level may not be reached. 
well into the most fibrous components of the mix, so that a uniform TMR results and sorting is held below $2 \%$ refusals (Jaynes, 2015). However, controlled studies are needed to evaluate this feeding technique from a rumen health point of view, because of the potentially reduced physical structure.

Furthermore, there is high inter-individual variation among cows in their susceptibility to highly fermentable diets. Studies have demonstrated that cows respond differently in ruminal $\mathrm{pH}$ dynamics when receiving the same concentrate-rich TMR (Gao and Oba, 2014; Humer et al., 2015b). Differences in feed sorting behavior might be one explanation for the large individual differences; SARA-susceptible cows seem to sort to a higher extent against long particles and for fine particles (Gao and Oba, 2014). Therefore, it is important to improve monitoring for early identification of high-risk cows, and to enable differentiated feeding management and individual treatment of the respective cows. Besides visual observations, a practical method to identify high-risk cows at an early stage as well as to evaluate structural fiber adequateness of diets could be to monitor chewing activity. Recently, several electronic devices have been proposed to replace time-consuming visual observations to measure the feeding behavior in dairy cows (Büchel and Sundrum, 2014; Ambriz-Vilchis et al., 2015; Kröger et al., 2016).

\section{Supplementation of Feed Additives}

During the last decades, there has been increasing interest in identifying feed additives that alleviate the risk of SARA in cattle. One commonly used approach is the stimulation of ruminal lactate-utilizing microorganisms, commonly via the addition of direct-fed microbials such as Saccharomyces cerevisiae, Lactobacillus plantarum, Selenomonas ruminantium, Megasphaera elsedenii, or Enterococcus faecium (Kleen et al., 2003; Nocek and Kautz, 2006; Henning et al., 2010; Poppy et al., 2012). Among them, yeast products are commonly included in diets of production animals, which can be provided as live yeast, dead yeasts, or yeast culture products. A meta-analysis by Desnoyers et al. (2009) revealed that supplementation of live yeast and yeast culture increased rumen $\mathrm{pH}(+0.03)$ while increasing SCFA concentration $(+2.17 \mathrm{mM})$, whereas lactic acid concentration was decreased by an average of $0.9 \mathrm{mM}$. It has been assumed that the positive effects of yeast products are not through direct action on $\mathrm{pH}$, but rather through a modulatory effect on the fermentation process and ruminal microbiome, such as by stimulation of lactate utilizers and an increase in certain cellulolytic bacteria and fungi (Calsamiglia et al., 2012). In this regard, Marden et al. (2008) ob- served an increase in ruminal $\mathrm{pH}$ when live yeast or bicarbonate were added to the diet; however, only diets supplemented with yeast caused a decrease in lactate concentration and improved fiber digestibility. Moreover, a recent study conducted by Kröger et al. (2017) found a positive effect of feeding autolyzed yeast in terms of improving ruminal $\mathrm{pH}$ dynamics in cattle fed $65 \%$ concentrate in the diet. A shift in the fermentation profile toward enhanced production of propionate in diets supplemented with live yeast as well as autolyzed yeast further strengthens the hypothesis of enhanced conversion of lactate to propionate, which might account for the pH-stabilizing effect of yeast products (Marden et al., 2008; Neubauer et al., 2017).

Besides direct-fed microbials, phytogenic compounds have been discussed as management tools to lower the risk of SARA. The underlying reasons might be a decrease in the starch-degradation rate (Jouany, 2006), an increased rumination activity (Kröger et al., 2017), or a modulatory effect on the ruminal fermentation profile toward enhanced production of butyrate (Neubauer et al., 2017). In this regard, Cardozo et al. (2006) observed reduced lactate concentrations in heifers fed diets supplemented with a mixture of cinnamaldehyde and eugenol. Moreover, Fandiño et al. (2008) found an enhanced proportion of butyrate in the ruminal fluid in heifers fed diets supplemented with capsicum as well as increased DMI, but no detrimental effect on ruminal $\mathrm{pH}$. However, neither study investigated or reported the mode of action of the products tested. Recently, a $\mathrm{pH}$-enhancing effect of a phytogenic feed additives was observed in dairy cows intermittently challenged with high-concentrate diets, whereby the effects were especially pronounced when lowest ruminal $\mathrm{pH}$ conditions prevailed (Kröger et al., 2017). Those changes went along with enhanced rumination activity of more than $60 \mathrm{~min} / \mathrm{h}$, a modulation of fermentation profile toward enhanced production of butyrate, and changes in the ruminal microbiome toward a decrease of starch utilizers (Neubauer et al., 2017). Thus, a delay in the onset of SCFA fermentation with concomitantly reduced SCFA accumulation might be the mechanisms behind the prevention of extended drops in $\mathrm{pH}$ by phytogenic compounds after feeding grain-rich diets.

Additionally, buffering substances, especially bicarbonates, have been routinely used in ruminant diets for their ruminal buffering capacity for more than $40 \mathrm{yr}$ and are well advocated in the therapy of acute ruminal acidosis (Krause and Oetzel, 2006; Calsamiglia et al., 2012). Bicarbonates are commonly used as exogenous buffers because their acid dissociation constant $\left(\mathrm{p} K_{\mathrm{a}}\right.$ $=6.25)$ is close to the normal ruminal $\mathrm{pH}$, thus, they possess a high acid-consuming capacity (Marden et al., 2008). Bicarbonates might prevent an overgrowth 
of acid-tolerant lactobacilli when high concentrate amounts are fed, thereby preventing further $\mathrm{pH}$ depression (Garry, 2002). Although buffers might be efficient in curing severe acidosis when applied as soon as the first symptoms emerge (Jouany, 2006), effects of feeding bicarbonates on ruminal $\mathrm{pH}$ are inconsistent in the scientific literature (Zinn, 1991; Paton et al., 2006). According to a meta-analysis conducted by $\mathrm{Hu}$ and Murphy (2005), $\mathrm{NaHCO}_{3}$ enhances ruminal $\mathrm{pH}$ by, on average, $0.13 \mathrm{pH}$ units. However, these effects were only found under certain conditions, such as in early- and mid-lactating cows and when diets had $>50 \%$ grains in the ration and corn silage was the forage source (Hu and Murphy, 2005; Calsamiglia et al., 2012). Another critical issue with using $\mathrm{NaHCO}_{3}$ is increased urinary $\mathrm{Na}$ excretion (Wu et al., 2015) with negative environmental effects, especially in countries with $\mathrm{Na}$ pollution problems. Overall, the effects of buffers - such as endogenous urea, dietary protein sources, or supplemental buffers such as sodium bicarbonate, urea, and oxides that are commonly supplemented in commercial dairy diets - mostly play only supportive roles in the overall ruminal acid-base balance of high-producing dairy cattle because their total effect on ruminal $\mathrm{pH}$ is relatively small (Krause and Oetzel, 2006; Gäbel et al., 2016).

In general, research efforts are increasing in the use of feed additives to enhance rumen health in cattle. Despite some contradictory results and, in many cases, unclarified modes of the action, the supplementation of feed additives including but not limited to yeast products, buffers, or phytogenic compounds might help during an acute problem with SARA or to alleviate its consequences on milk composition, especially during challenging conditions such as early lactation. In either case, supplementation of feed additives can help but cannot compensate for suboptimal feeding management, whereas proper feeding management can help to reduce the need for feed additive supplementation. More research is warranted to establish the mode of the action of feed additives, particularly in the rumen.

\section{CONCLUSIONS}

Ensuring efficient and near-maximal nutrient utilization while minimizing the risk for digestive upset are important variables in the equation of sustainable and profitable milk production and pose a continuous challenge to dairy nutritionists. Overall, the provision of sufficient physically effective fiber while feeding adequate amounts of fermentable nutrients is essential to meet the requirements of a healthy rumen ecosystem and still ensuring maximum performance and feed ef- ficiency. To prevent SARA and its sequelae, consideration must be given to the appropriate adaptation of the rumen microbial communities and the rumen SSE to energy-dense diets in early lactation. Overall, feeding management plays the largest role in SARA prevention and management and should consider not only the differences between primiparous and multiparous cows and stage of lactation but also the specifics of feeding on farms of different sizes.

\section{ACKNOWLEDGMENTS}

Research of Q. Zebeli has been funded by Deutsche Forschungsgemeinschaft (DFG, Bonn, Germany), Austrian Research Promotion Agency (FFG, Vienna, Austria) under the scope of the COMET program "ADDA - Advancement of Dairying in Austria" as well as Vienna Science and Technology Fund (WWTF, Vienna, Austria) under the project "D-I.INFLACOW, LS12-010," and the Austrian Federal Ministry of Agriculture, Forestry, Environment and Water Management (BMLFUW, Vienna, Austria) under the project "optGerste," which are gratefully acknowledged.

\section{REFERENCES}

Albornoz, R. I., J. R. Aschenbach, D. R. Barreda, and G. B. Penner. 2013. Moderate decreases in the forage-to-concentrate ratio before feed restriction and increases thereafter independently improve the recovery from a feed restriction insult in beef cattle. J. Anim. Sci. 91:4739-4749.

Allen, M. S. 1997. Relationship between fermentation acid production in the rumen and the requirement for physically effective fiber. J. Dairy Sci. 80:1447-1462.

Ambriz-Vilchis, V., N. S. Jessop, R. H. Fawcett, D. J. Shaw, and A. I. Macrae. 2015. Comparison of rumination activity measured using rumination collars against direct visual observations and analysis of video recordings of dairy cows in commercial farm environments. J. Dairy Sci. 98:1750-1758.

Aschenbach, J. R., S. Bilk, G. Tadesse, F. Stumpff, and G. Gäbel. 2009. Bicarbonate-dependent and bicarbonate-independent mechanisms contribute to nondiffusive apical uptake of acetate in the ruminal epithelium of sheep. Am. J. Physiol. Gastrointest. Liver Physiol. 296:G1098-G1107.

Aschenbach, J. R., N. B. Kristensen, S. S. Donkin, H. M. Hammon, and G. B. Penner. 2010. Gluconeogenesis in dairy cows: The secret of making sweet milk from sour dough. IUBMB Life 62:869-877.

Aschenbach, J. R., G. B. Penner, F. Stumpff, and G. Gäbel. 2011. Ruminant nutrition symposium: Role of fermentation acid absorption in the regulation of ruminal pH. J. Anim. Sci. 89:1092-1107.

Bach, A., C. Iglesias, S. Calsamiglia, and M. Devant. 2007. Effect of amount of concentrate offered in automatic milking systems on milking frequency, feeding behavior, and milk production of dairy cattle consuming high amounts of corn silage. J. Dairy Sci. 90:5049-5055.

Bannink, A., W. J. J. Gerrits, J. France, and J. Dijkstra. 2012. Variation in rumen fermentation and the rumen wall during the transition period in dairy cows. Anim. Feed Sci. Technol. 172:80-94.

Bargo, F., L. D. Muller, J. E. Delahoy, and T. W. Cassidy. 2002. Performance of high producing dairy cows with different feeding systems combining pasture and total mixed rations. J. Dairy Sci. 85:2948-2963. 
Beauchemin, K. A., and W. Yang. 2005. Effects of physically effective fiber on intake, chewing activity, and ruminal acidosis for dairy cows fed diets based on corn silage. J. Dairy Sci. 88:2117-2129.

Benninghoff, J., M. Paschke-Beese, and K.-H. Südekum. 2015. In situ and in vitro ruminal degradation of maize grain and untreated or xylose-treated wheat, barley and rye grains. Anim. Feed Sci. Technol. 210:86-93.

Boddugari, K., R. Grant, R. Stock, and M. Lewis. 2001. Maximal replacement of forage and concentrate with a new wet corn milling product for lactating dairy cows. J. Dairy Sci. 84:873-884.

Bowman, G. R., K. Beauchemin, and J. Shelford. 2003. Fibrolytic enzymes and parity effects on feeding behavior, salivation, and ruminal pH of lactating dairy cows. J. Dairy Sci. 86:565-575.

Bradford, B. J., and M. S. Allen. 2007. Depression in feed intake by a highly fermentable diet is related to plasma insulin concentration and insulin response to glucose infusion. J. Dairy Sci. 90:38383845 .

Bradford, B. J., and C. R. Mullins. 2012. Invited review: Strategies for promoting productivity and health of dairy cattle by feeding nonforage fiber sources. J. Dairy Sci. 95:4735-4746.

Bramley, E., I. Lean, W. Fulkerson, M. Stevenson, A. Rabiee, and N. Costa. 2008. The definition of acidosis in dairy herds predominantly fed on pasture and concentrates. J. Dairy Sci. 91:308-321.

Büchel, S., and A. Sundrum. 2014. Technical note: Evaluation of a new system for measuring feeding behavior of dairy cows. Comput. Electron. Agric. 108:12-16.

Calsamiglia, S., M. Blanch, A. Ferret, and D. Moya. 2012. Is subacute ruminal acidosis a $\mathrm{pH}$ related problem? Causes and tools for its control. Anim. Feed Sci. Technol. 172:42-50.

Cardozo, P. W., S. Calsamiglia, A. Ferret, and C. Kamel. 2006. Effects of alfalfa extract, anise, capsicum, and a mixture of cinnamaldehyde and eugenol on ruminal fermentation and protein degradation in beef heifers fed a high-concentrate diet. J. Anim. Sci. 84:2801-2808.

Carta, P. 2010. The physically effective fiber of total mixed rations and its effects on dairy cow performance. PhD Thesis. University of Sassari, Italy.

Cassida, K. A., and M. R. Stokes. 1986. Eating and resting salivation in early lactation dairy cows. J. Dairy Sci. 69:1282-1292.

Charmley, E. 2001. Towards improved silage quality-A review. Can. J. Anim. Sci. 81:157-168.

Chibisa, G. E., K. A. Beauchemin, and G. B. Penner. 2016. Relative contribution of ruminal buffering systems to $\mathrm{pH}$ regulation in feedlot cattle fed either low- or high-forage diets. Animal 10:1164-1172.

Cistola, D. P., D. M. Small, and J. A. Hamilton. 1982. Ionization behaviour of aqueous short-chain carboxylic acids: A carbon-13 NMR study. J. Lipid Res. 23:795-799.

Coppock, C. E. 1987. Supplying the energy and fiber needs of dairy cows from alternate feed sources. J. Dairy Sci. 70:1110-1119.

DeVries, T. J., F. Dohme, and K. A. Beauchemin. 2008. Repeated ruminal acidosis challenges in lactating dairy cows at high and low risk for developing acidosis: Feed sorting. J. Dairy Sci. 91:39583967.

DeVries, T. J., and M. A. von Keyserlingk. 2005. Time of feed delivery affects the feeding and lying patterns of dairy cows. J. Dairy Sci 88:625-631.

DeVries, T. J., M. A. von Keyserlingk, and K. A. Beauchemin. 2005 Frequency of feed delivery affects the behavior of lactating dairy cows. J. Dairy Sci. 88:3553-3562.

DeVries, T. J., M. A. von Keyserlingk, and D. M. Weary. 2004. Effect of feeding space on the inter-cow distance, aggression, and feeding behavior of free-stall housed lactating dairy cows. J. Dairy Sci. $87: 1432-1438$.

Desnoyers, M., S. Giger-Reverdin, G. Bertin, C. Duvaux-Ponter, and D. Sauvant. 2009. Meta-analysis of the influence of Saccharomyces cerevisiae supplementation on ruminal parameters and milk production in ruminants. J. Dairy Sci. 92:1620-1632.

Dieho, K., A. Bannink, I. A. L. Geurts, J. T. Schonewille, G. Gort, and J. Dijkstra. 2016. Morphological adaptation of rumen papillae during the dry period and early lactation as affected by rate of increase of concentrate allowance. J. Dairy Sci. 99:2339-2352.
Dieho, K., J. Dijkstra, G. Klop, J. T. Schonewille, and A. Bannink. 2017. Changes in rumen microbiota composition and in situ degradation kinetics during the dry period and early lactation as affected by rate of increase of concentrate allowance. J. Dairy Sci. 100:2695-2710.

Dirksen, G. 1985. The rumen acidosis complex-Recent knowledge and experiences (1): A review. Tierarztl. Prax. 13:501-512.

Dohme, F., T. De Vries, and K. Beauchemin. 2008. Repeated ruminal acidosis challenges in lactating dairy cows at high and low risk for developing acidosis: Ruminal pH. J. Dairy Sci. 91:3554-3567.

Dulphy, J. P., and M. Van Os. 1996. Control and voluntary intake of precision-chopped silages by ruminants: A review. Reprod. Nutr. Dev. 36:113-135.

Erickson, G. E., C. T. Milton, K. C. Fanning, R. J. Cooper, R. S. Swingle, J. C. Parrot, G. Vogel, and T. J. Klopfenstein. 2003. Interaction between bunk management and monensin concentration on finishing performance, feeding behaviour, and ruminal metabolism during an acidosis challenge with feedlot cattle. J. Anim. Sci. 81:2869-2879.

Fandiño, I., S. Calsamiglia, A. Ferret, and M. Blanch. 2008. Anise and capsicum as alternatives to monensin to modify rumen fermentation in beef heifers fed a high concentrate diet. Anim. Feed Sci. Technol. 145:409-417.

Faverdin, P., J. P. Dulphy, J. B. Coulon, R. Vérité, J. P. Garel, J. Rouel, and B. Marquis. 1991. Substitution of roughage by concentrates for dairy cows. Livest. Prod. Sci. 27:137-156.

Ferraretto, L. F., and R. D. Shaver. 2012. Effect of corn shredlage on lactation performance and total tract starch digestibility by dairy cows. Prof. Anim. Sci. 28:639-647.

Gäbel, G., J. R. Aschenbach, and F. Müller. 2002. Transfer of energy substrates across the ruminal epithelium: Implications and limitations. Anim. Health Res. Rev. 3:15-30.

Gäbel, G., J. R. Aschenbach, and R. Rackwitz. 2016. Sauer ist nicht immer lustig: Kann sich der Vormagen gegen die Säurebelastung verteidigen? In: 8. Leipziger Tierärztekongress Teil: Tagungsband 3., Wiederkäuer, Schweine, Nutzgeflügel, Fische, DVG-Symposium, Bienen, Veterinary Public Health, Recht und Beruf. J. R. Aschenbach, ed. Lehmanns Media GmbH, Berlin, Germany.

Gao, X., and M. Oba. 2014. Relationship of severity of subacute ruminal acidosis to rumen fermentation, chewing activities, sorting behavior, and milk production in lactating dairy cows fed a highgrain diet. J. Dairy Sci. 97:3006-3016.

Garry, F. B. 2002: Indigestion in ruminants. Pages 722-747 in Large Animal Internal Medicine. 3rd ed. B. P. Smith, ed. Mosby, St. Louis, MO.

GfE (Gesellschaft für Ernährungsphysiologie). 2014. Communications of the committee for requirement standards of the society of nutrition physiology: Evaluation of structural effectiveness of mixed rations for dairy cows-Status and perspectives. Pages 165-179. Vol. 23. Proc. Soc. Nutr. Physiol., ed. DLG-Verlag, Frankfurt, Germany.

González, L. A., X. Manteca, S. Calsamiglia, K. S. SchwartzkopfGenswein, and A. Ferret. 2012. Ruminal acidosis in feedlot cattle: Interplay between feed ingredients, rumen function and feeding behavior (a review). Anim. Feed Sci. Technol. 172:66-79.

Gressley, T. F., M. B. Hall, and L. E. Armentano. 2011. Ruminant Nutrition Symposium: Productivity, digestion, and health responses to hindgut acidosis in ruminants. J. Anim. Sci. 89:1120-1130.

Gröhn, Y., and M. Bruss. 1990. Effect of diseases, production, and season on traumatic reticuloperitonitis and ruminal acidosis in dairy cattle. J. Dairy Sci. 73:2355-2363.

Gruber, L., M. Pries, F. J. Schwarz, H. Spiekers, and W. Staudacher. 2006. Schätzung der Futteraufnahme bei der Milchkuh. DLG-Information 1:10-19.

Harmon, D. L., R. M. Yamka, and N. A. Elam. 2004. Factors affecting intestinal starch digestion in ruminants: A review. Can. J. Anim. Sci. 84:309-318.

Hayirli, A., R. R. Grummer, E. V. Nordheim, and P. M. Crump. 2003. Models for predicting dry matter intake of Holsteins during the prefresh transition period. J. Dairy Sci. 86:1771-1779. 
Heinrichs, J., and P. Kononoff. 2002. Evaluating particle size of forages and TMRs using the new Penn State Forage Particle Separator. Pages 1-15.

Henning, P. H., C. H. Horn, D. G. Steyn, H. H. Meissner, and F. M. Hagg. 2010. The potential of Megasphaera elsdenii isoaltes to control ruminal acidosis. Anim. Feed Sci. Technol. 157:13-19.

Hills, J. L., W. J. Wales, F. R. Dunshea, S. C. Garcia, and J. R. Roche. 2015. Invited review: An evaluation of the likely effects of individualized feeding of concentrate supplements to pasture-based dairy cows. J. Dairy Sci. 98:1363-1401.

Ho, C. K. M., B. Malcom, and P. T. Doyle. 2013. Potential impacts of negative associative effects between concentrate supplements, pasture and conserved forage for milk production and dairy farm profit. Anim. Prod. Sci. 53:437-452.

Hosseinkhani, A., T. J. De Vries, K. L. Proudfoot, R. Valizadeh, D. M. Veira, and M. A. von Keyserlingk. 2008. The effects of feed bunk competition on the feed sorting behavior of close-up dry cows. J. Dairy Sci. 91:1115-1121.

Hu, W., and M. R. Murphy. 2005. Statistical evaluation of early- or mid-lactation dairy cow responses to dietary sodium bicarbonate addition. Anim. Feed Sci. Technol. 119:43-54.

Humer, E., K. Ghareeb, H. Harder, E. Mickdam, A. Khol-Parisini, and Q. Zebeli. 2015b. Peripartal changes in reticuloruminal $\mathrm{pH}$ and temperature in dairy cows differing in the susceptibility to subacute rumen acidosis. J. Dairy Sci. 98:8788-8799.

Humer, E., A. Khol-Parisini, L. Gruber, J. Gasteiner, S. Abdel-Raheem, and Q. Zebeli. 2015a. Long-term reticuloruminal $\mathrm{pH}$ dynamics and markers of liver health in early-lactating cows of various parities fed diets differing in grain processing. J. Dairy Sci. 98:6433-6448

Humer, E., and Q. Zebeli. 2017. Grains in ruminant feeding and potentials to enhance their nutritive and health value by chemical processing. Anim. Feed Sci. Technol. 226:133-151.

Huzzey, J. M., T. J. De Vries, P. Valois, and M. A. von Keyserlingk. 2006. Stocking density and feed barrier design affect the feeding and social behavior of dairy cattle. J. Dairy Sci. 89:126-133.

Jaynes, L. 2015. Compact TMR from Denmark. Accessed Sep. 6, 2017. http://www.progressivedairy.com/topics/feed-nutrition/compact -tmr-from-denmark.

Jiang, F. G., X. Y. Lin, Z. G. Yan, Z. Y. Hu, G. M. Liu, Y. D. Sun X. W. Liu, and Z. H. Wang. 2017. Effect of dietary roughage level on chewing activity, ruminal $\mathrm{pH}$, and saliva secretion in lactating Holstein cows. J. Dairy Sci. 100:2660-2671.

Jouany, J. P. 2006. Optimizing rumen functions in the close-up transition period and early lactation to drive dry matter intake and energy balance in cows. Anim. Reprod. Sci. 96:250-264.

Khan, N. A., P. Yu, M. Ali, J. W. Cone, and W. H. Hendriks. 2015 Nutritive value of maize silage in relation to dairy cow performance and milk quality. J. Sci. Food Agric. 95:238-252.

Kleefisch, M. T., Q. Zebeli, E. Humer, I. Kröger, P. Ertl, and F. Klevenhusen. 2017. Effects of the replacement of concentrate and fibre-rich hay by high-quality hay on chewing, rumination and nutrient digestibility in non-lactating Holstein cows. Arch. Anim. Nutr. 71:21-36.

Kleen, J. L., G. Hooijer, J. Rehage, and J. Noordhuizen. 2003. Subacute ruminal acidosis (SARA): A review. J. Vet. Med. A Physiol. Pathol. Clin. Med. 50:406-414.

Kohn, R. A., and T. F. Dunlap. 1998. Calculation of the buffering capacity of bicarbonate in the rumen and in vitro. J. Anim. Sci 76:1702-1709

Kononoff, P. J., A. J. Heinrichs, and D. R. Buckmaster. 2003. Modification of the Penn State forage and total mixed ration particle separator and the effects of moisture content on its measurements. J. Dairy Sci. 86:1858-1863.

Krause, K., and G. Oetzel. 2006. Understanding and preventing subacute ruminal acidosis in dairy herds: A review. Anim. Feed Sci. Technol. 126:215-236.

Kröger, I., E. Humer, V. Neubauer, N. Kraft, P. Ertl, and Q. Zebeli. 2016. Validation of a noseband sensor system for monitoring ruminating activity in cows under different feeding regimens. Livest. Sci. 193:118-122.
Kröger, I., E. Humer, V. Neubauer, N. Reisinger, S. Adytia, and Q. Zebeli. 2017. Modulation of chewing behavior and reticular $\mathrm{pH}$ in non-lactating cows challenged with concentrate-rich diets supplemented with phytogenic compounds and autolyzed yeast. J. Dairy Sci. 100:9702-9714. https://doi.org/10.3168/jds.2017-12755.

Lammers, B. P., D. Buckmaster, and A. Heinrichs. 1996. A simple method for the analysis of particle sizes of forage and total mixed rations. J. Dairy Sci. 79:922-928.

Lanzas, C. C. J. Sniffen, S. al Seo, L. O. Tedeschi, and D. G. Fox. 2007. A revised CNCPS feed carbohydrate fractionation scheme for formulating rations for ruminants. Anim. Feed Sci. Technol. $136: 167-190$.

Leonardi, C., and L. Armentano. 2003. Effect of quantity, quality, and length of alfalfa hay on selective consumption by dairy cows. J. Dairy Sci. 86:557-564.

Leonardi, C., F. Giannico, and L. E. Armentano. 2005. Effect of water addition on selective consumption (sorting) of dry diets by dairy cattle. J. Dairy Sci. 88:1043-1049.

Lüscher, A., I. Mueller-Harvey, J. F. Soussana, R. M. Rees, and J. L. Peyraud. 2014. Potential of legume-based grassland-livestock systems in Europe: A review. Grass Forage Sci. 69:206-228.

Macmillan, K., X. Gao, and M. Oba. 2017. Increased feeding frequency increased milk fat yield and may reduce the severity of subacute ruminal acidosis in higher-risk cows. J. Dairy Sci. 100:1045-1054.

Maekawa, M., K. Beauchemin, and D. Christensen. 2002. Effect of concentrate level and feeding management on chewing activities, saliva production, and ruminal $\mathrm{pH}$ of lactating dairy cows. J. Dairy Sci. 85:1165-1175

Marden, J. P., C. Julien, V. Monteils, E. Auclair, R. Moncoulon, and C. Bayourthe. 2008. How does live yeast differ from sodium bicarbonate to stabilize ruminal $\mathrm{pH}$ in high-yielding dairy cows? J. Dairy Sci. 91:3528-3535.

Matthé, A., P. Lebzien, I. Hric, G. Flachowsky, and A. Sommer. 2001 Effect of starch application into the proximal duodenum of ruminants on starch digestibility in the small and total intestine. Arch. Tierernahr. 55:351-369.

McCann, J. C., T. A. Wickersham, and J. J. Loor. 2014. Rumen microbiome and its relationship with nutrition and metabolism. Bioinform. Biol. Insights 8:109-125.

Mertens, D. R. 1997. Creating a system for meeting the fiber requirements of dairy cows. J. Dairy Sci. 80:1463-1481.

Moharrery, A., M. Larsen, and M. R. Weisbjerg. 2014. Starch digestion in the rumen, small intestine, and hind gut of dairy cows- $\mathrm{A}$ meta-analysis. Anim. Feed Sci. Technol. 192:1-14.

Müller, F., K. Huber, H. Pfannkuche, J. R. Aschenbach, G. Breves, and G. Gäbel. 2002. Transport of ketone bodies and lactate in the sheep ruminal epithelium by monocarboxylate transporter 1 . Am. J. Physiol. Gastrointest. Liver Physiol. 283:G1139-G1146.

Naik, P. K. 2013. Bypass fat in dairy ration-A review. Anim. Nutr. Feed Technol. 13:147-163.

Nasrollahi, S. M., A. Zali, G. R. Ghorbani, M. Moradi Shahrbabak, M. Heydari Soltan Abadi, and L. A. Krueger. 2017. Variability in the susceptibility to acidosis among high producing mid-lactation dairy cows is associated with rumen $\mathrm{pH}$, fermentation, feed intake, sorting activity, and milk fat percentage. Anim. Feed Sci. Technol. $228: 72-82$

Neubauer, V., R. Petri, E. Humer, I. Kröger, E. Mann, N. Reisinger, M. Wagner, and Q. Zebeli. 2018. High-grain diets supplemented with phytogenic compounds or autolyzed yeast modulate ruminal bacterial community and fermentation in dry cows. J. Dairy Sci. https://doi.org/10.3168/jds.2017-13565.

Nocek, J. E. 1997. Bovine acidosis: Implications on laminitis. J. Dairy Sci. 80:1005-1028.

Nocek, J. E., and W. P. Kautz. 2006. Direct-fed microbial supplementation on ruminal digestion, health, and performance of pre- and postpartum dairy cattle. J. Dairy Sci. 89:260-266.

Nordlund, K., E. Garrett, and G. Oetzel. 1995. Herd-based ruminocentesis - A clinical approach to the diagnosis of subacute rumen acidosis. Comp. Cont. Educ. Pract. 17:48-56.

NRC. 2001. Nutrient Requirements of Dairy Cattle. 7th rev. ed. National Academies Press, Washington, DC. 
Oelberg, T. J., and W. Stone. 2014. Monitoring total mixed rations and feed delivery systems. Vet. Clin. North Am. Food. Anim. Pract. 30:721-744.

Oetzel, G. R. 2000. Clinical aspects of ruminal acidosis in dairy cattle. Pages 46-53 in Proc. 33rd Annu. Conv. Am. Assoc. Bovine Pract., Rapid City, IA. Am. Assoc. Bovine Pract., Auburn, AL.

Oetzel, G. R. 2007. Subacute ruminal acidosis in dairy herds: Physiology, pathophysiology, milk fat responses and nutritional management. Pages 89-119 in Am. Assoc. Bovine Pract. 40th Annual Conf., Vancouver, BC, Canada. University of Wisconsin, Madison.

Offner, A., A. Bach, and D. Sauvant. 2003. Quantitative review of in situ starch degradation in the rumen. Anim. Feed Sci. Technol. 106:81-93.

Owens, F. 2005. Corn grain processing and digestion. Pages 1-21 in Proc. Minn. Nutr. Conf., St. Paul, MN. DuPont Pioneer, Johnston, IA.

Paton, L. J., K. A. Beauchemin, D. M. Veira, and M. A. G. von Keyserlingk. 2006. Use of sodium bicarbonate, offered free choice or blended into the ration, to reduce the risk of ruminal acidosis in cattle. Can. J. Anim. Sci. 86:429-437.

Patton, R. A., J. R. Patton, and S. E. Boucher. 2012. Defining ruminal and total-tract starch degradation for adult dairy cattle using in vivo data. J. Dairy Sci. 95:765-782.

Penner, G. B., J. R. Aschenbach, G. Gäbel, R. Rackwitz, and M. Oba. 2009. Epithelial capacity for apical uptake of short chain fatty acids is a key determinant for intraruminal $\mathrm{pH}$ and the susceptibility to sub-acute ruminal acidosis in sheep. J. Nutr. 139:1714-1720.

Penner, G. B., K. Beauchemin, and T. Mutsvangwa. 2007. Severity of ruminal acidosis in primiparous Holstein cows during the periparturient period. J. Dairy Sci. 90:365-375.

Penner, G. B., M. A. Steele, J. R. Aschenbach, and B. W. McBride. 2011. Ruminant Nutrition Symposium: Molecular adaptation of ruminal epithelia to highly fermentable diets. J. Anim. Sci. 89:1108-1119.

Plaizier, J. C., E. Khafipour, S. Li, G. N. Gozho, and D. O. Krause. 2012. Subacute ruminal acidosis (SARA), endotoxins and health consequences. Anim. Feed Sci. Technol. 172:9-21.

Plaizier, J. C., D. O. Krause, G. N. Gozho, and B. W. McBride. 2008. Subacute ruminal acidosis in dairy cows: The physiological causes, incidence and consequences. Vet. J. 176:21-31.

Plaizier, J. C., S. Li, A. M. Danscher, H. Derakshani, P. H. Andersen, and E. Khafipour. 2017. Changes in microbiota in rumen digesta and feces due to a grain-based subacute ruminal acidosis (SARA) challenge. Microb. Ecol. 74:485-495.

Poppi, D. P., W. Ellis, J. Matis, and C. Lascano. 2001. Marker concentration patterns of labelled leaf and stem particles in the rumen of cattle grazing bermuda grass (Cynodon dactylon) analysed by reference to a raft model. Br. J. Nutr. 85:553-563.

Poppy, G. D., A. R. Rabiee, I. J. Lean, W. K. Sanchez, K. L. Dorton, and P. S. Morley. 2012. A meta-analysis of the effects of feeding yeast culture produced by anaerobic fermentation of Saccharomyces cerevisiae on milk production of lactating dairy cows. J. Dairy Sci. 95:6027-6041.

Pourazad, P., R. Khiaosa-ard, M. Qumar, S. Wetzels, F. Klevenhusen, B. Metzler-Zebeli, and Q. Zebeli. 2016. Transient feeding of a concentrate-rich diet increases the severity of subacute ruminal acidosis in dairy cattle. J. Anim. Sci. 94:726-738.

Qumar, M., R. Khiaosa-ard, F. Pourazad, S. Wetzels, F. Klevenhusen, W. Kandler, J. Aschenbach, and Q. Zebeli. 2016. Evidence of in vivo absorption of lactate and modulation of short chain fatty acid absorption from the reticulorumen of non-lactating cattle fed high concentrate diets. PLoS One 11:e0164192. https://doi.org/10 .1371/journal.pone.0164192.

Rabelo, E., R. L. Rezende, S. J. Bertics, and R. R. Grummer. 2003. Effects of transition diets varying in dietary energy density on lactational performance and ruminal parameters of dairy cows. J. Dairy Sci. 86:916-925.

Rioja-Lang, F. C., D. J. Roberts, S. D. Healy, A. B. Lawrence, and M. J. Haskell. 2012. Dairy cow feeding space requirements assessed in a Y-maze choice test. J. Dairy Sci. 95:3954-3960.
Roche, J. R., A. W. Bell, T. R. Overton, and J. L. Loor. 2013. Nutritional management of the transition cow in the 21st century-A paradigm shift in thinking. Anim. Prod. Sci. 53:1000-1023.

Schurmann, B. L., M. E. Walpole, P. Gorka, J. C. H. Ching, M. E. Loewen, and G. B. Penner. 2014. Short-term adaptation of the ruminal epithelium involves abrupt changes in sodium and shortchain fatty acid transport. Am. J. Physiol. Regul. Integr. Comp. Physiol. 307:R802-R816.

Schwaiger, T., K. A. Beauchemin, and G. B. Penner. 2013a. Duration of time that beef cattle are fed a high-grain diet affects the recovery from a bout of ruminal acidosis: Short-chain fatty acid and lactate absorption, saliva production, and blood metabolites. J. Anim. Sci. 91:5743-5753.

Schwaiger, T., K. A. Beauchemin, and G. B. Penner. 2013b. The duration of time that beef cattle are fed a high-grain diet affects the recovery from a bout of ruminal acidosis: Dry matter intake and ruminal fermentation. J. Anim. Sci. 91:5729-5742.

Seglar, W. J., and R. D. Shaver. 2014. Management and assessment of ensiled forages and high-moisture grain. Vet. Clin. North Am. Food Anim. Pract. 30:507-538.

Shaver, R. D. 2002. Rumen acidosis in dairy cattle: Bunk management considerations. Pages 75-81 in Proc. 12th Int. Symp. on Lameness in Ruminants, Orlando, FL. J. K. Shearer, ed. University of Wisconsin, Madison.

Silveira, C., M. Oba, W. Z. Yang, and K. A. Beauchemin. 2007. Selection of barley grain affects ruminal fermentation, starch digestibility, and productivity of lactating dairy cows. J. Dairy Sci. 90:2860-2869.

Steele, M. A., J. C. Croom, M. Kahler, O. AlZahal, S. E. Hook, K. Plaizier, and B. W. McBride. 2011. Bovine rumen epithelium undergoes rapid structural adaptations during grain-induced subacute ruminal acidosis. Am. J. Physiol. Regul. Integr. Comp. Physiol. 300:R1515-1523.

Steele, M. A., G. B. Penner, F. Chaucheyras-Durand, and L. Guan. 2016. Development and physiology of the rumen and the lower gut: Targets for improving gut health. J. Dairy Sci. 99:4955-4966.

Steele, M. A., C. Schiestel, O. AlZahal, L. Dionissopoulos, A. H. Laarman, J. C. Matthews, and B. W. McBride. 2015. The periparturient period is associated with structural and transcriptomic adaptions of rumen papillae in dairy cattle. J. Dairy Sci. 98:2583-2595.

Stone, W. C. 2004. Nutritional approaches to minimize subacute ruminal acidosis and laminitis in dairy cattle. J. Dairy Sci. 87:E13-E26.

Storm, A. C., and N. B. Kristensen. 2010. Effects of particle size and dry matter content of total mixed ration on intraruminal equilibration and net portal flux of volatile fatty acids in lactating dairy cows. J. Dairy Sci. 93:4223-4238.

Storm, A. C., N. B. Kristensen, and M. D. Hanigan. 2012. A model of ruminal volatile fatty acid absorption kinetics and rumen epithelial blood flow in lactating Holstein cows. J. Dairy Sci. 95:2919-2934.

Südekum, K.-H., S. J. Krizsan, and K. Gerlach. 2016. Forage quality evaluation-Current trends and future prospects. Pages 151-158 in The Multiple Roles of Grassland in the European Bioeconomy. Proc. 26th Gen. Meet. Europ. Grassl. Fed. Wageningen Academic Publishers, Wageningen, the Netherlands.

Tafaj, M., B. Junck, A. Maulbetsch, H. Steingass, H.-P. Piepho, and W. Drochner. 2004. Digesta characteristics of dorsal, middle and ventral rumen of cows fed with different hay qualities and concentrates levels. Arch. Anim. Nutr. 58:325-342.

Tafaj, M., V. Kolaneci, B. Junck, A. Maulbetsch, H. Steingass, and W. Drochner. 2005. Influence of fiber content and concentrate level on chewing activity, ruminal digestion, digesta passage rate and nutrient digestibility in dairy cows in late lactation. Asian-australas. J. Anim. Sci. 18:1116-1124.

Van Soest, P. 1967. Development of a comprehensive system of feed analyses and its application to forages. J. Anim. Sci. 26:119-128.

Vanderwerff, L. M., L. F. Ferraretto, and R. D. Shaver. 2015. Brown midrib corn shredlage in diets for high-producing dairy cows. J. Dairy Sci. 98:5642-5652.

Varga, G. A., H. Dann, and V. Ishler. 1998. The use of fiber concentrations for ration formulation. J. Dairy Sci. 81:3063-3074 
Vibart, R. E., V. Fellner, J. C. Burns, G. B. Huntington, and J. T. Green. 2008. Performance of lactating dairy cows fed varying levels of total mixed rations and pasture. J. Dairy Res. 75:471-480.

Wetzels, S. U., E. Mann, P. Pourazad, M. Qumar, B. Pinior, B. U. Metzler-Zebeli, M. Wagner, S. Schmitz-Esser, and Q. Zebeli. 2017. Epimural bacterial community structure in the rumen of Holstein cows with different responses to a long-term subacute ruminal acidosis diet challenge. J. Dairy Sci. 100:1829-1844.

Wu, Z., J. K. Bernard, and S. J. Taylor. 2015. Effect of feeding calcareous marine algae to Holstein cows prepartum or postpartum on serum metabolites and performance. J. Dairy Sci. 98:4629-4639.

Yang, W. Z., K. Beauchemin, and L. Rode. 2002. Effects of particle size of alfalfa-based dairy cow diets on site and extent of digestion. J. Dairy Sci. 85:1958-1968.

Zebeli, Q., J. R. Aschenbach, M. Tafaj, J. Boghun, B. N. Ametaj, and W. Drochner. 2012. Invited review: Role of physically effective fiber and estimation of dietary fiber adequacy in high-producing dairy cattle. J. Dairy Sci. 95:1041-1056.

Zebeli, Q., J. Dijkstra, M. Tafaj, H. Steingass, B. Ametaj, and W. Drochner. 2008. Modeling the adequacy of dietary fiber in dairy cows based on the responses of ruminal $\mathrm{pH}$ and milk fat production to composition of the diet. J. Dairy Sci. 91:2046-2066.

Zebeli, Q., and E. Humer. 2016a. Ausreichend Struktur in der Milchviehration? Von der Bewertung zur adäquaten Versorgung. Pages
21-27 in 43. Viehwirtschaftliche Fachtagung. Raumberg-Gumpenstein, Austria. Bericht HBLFA Raumberg-Gumpenstein, Austria.

Zebeli, Q., and E. Humer. 2016b. Gesunde und hochleistende Milchkühe: eine Frage des Kompromisses zwischen Struktur- und Energieversorgung. Klauentierpraxis 24:49-53.

Zebeli, Q., D. Mansmann, B. Ametaj, H. Steingass, and W. Drochner. 2010. A model to optimise the requirements of lactating dairy cows for physically effective neutral detergent fibre. Arch. Anim. Nutr. $64: 265-278$

Zebeli, Q., and B. U. Metzler-Zebeli. 2012. Interplay between rumen digestive disorders and diet-induced inflammation in dairy cattle. Res. Vet. Sci. 93:1099-1108.

Zebeli, Q., M. Tafaj, H. Steingass, B. Metzler, and W. Drochner. 2006. Effects of physically effective fiber on digestive processes and milk fat content in early lactating dairy cows fed total mixed rations. J. Dairy Sci. 89:651-668.

Zhang, S., R. I. Albornoz, J. R. Aschenbach, D. R. Barreda, and G. B. Penner. 2013. Short-term feed restriction impairs the absorptive function of the reticulo-rumen and total tract barrier function in beef cattle. J. Anim. Sci. 91:1685-1695.

Zinn, R. A. 1991. Comparative feeding value of steam-flaked corn and sorghum in finishing diets supplemented with or without sodium bicarbonate. J. Anim. Sci. 69:905-916. 